\title{
Research Paper: The Relationship Between Weight Effi- cacy Life Style Dimensions and Perceived Parental Styles Dimensions with Psychological Well-being in Students
}

\author{
Ezzatollah Ahmadi $^{1}$ (D), Seyedeh Arezoo Kazemi ${ }^{\text {1* }}$ (i)
}

1. Department of Psychology, Faculty of Education and Psychology, Azarbaijan Shahid Madani University, Tabriz, Iran.

$\begin{array}{ll}\begin{array}{l}\text { Use your device to scan } \\ \text { and read the article online }\end{array} & \begin{array}{l}\text { Crtation Ahmadi E, Kazemi SA. The Relationship Between Weight Efficacy Life Style Dimensions and Perceived Paren- } \\ \text { tal Styles Dimensions With Psychological Well-being in Students. Journal of Research \& Health. 2021; 11(2):123-130. http:// } \\ \text { dx.doi.org/10.32598/JRH.11.2.1639.2 }\end{array} \\ \text { dol: }: \text { http://dx.doi.org/10.32598/JRH.11.2.1639.2 }\end{array}$

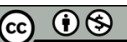

Article info:

Received: 30 Mar 2019

Accepted: 20 Nov 2019

Publish: 01 Apr 2021

Keywords:

Health, Life style, Parenting

\section{A B STRACT}

Background: Psychological well-being is a multidimensional concept that is typically defined as a mixture of positive affective states, such as satisfaction and functioning with optimum life efficiency. The aim of this study was to examine the relationship between weight efficacy lifestyle dimensions and perceived parental styles dimensions with psychological well-being among university students.

Methods: The statistical population of this correlational study was all undergraduate and master students of Azarbaijan Shahid Madani University in the academic year 2016-2017, of whom 180 students were selected through multi-stage random cluster sampling. They were assessed by Clark's Weight Efficacy Life Style (WEL), Grolnick's Perceptions of Parents Scales (POPS), and Keyes \& Magyar-Moe's Psychological Well-being questionnaires. In addition, the demographic questionnaire was completed. Data were analyzed by SPSS V. 24 using descriptive statistics and simultaneous regression.

Results: According to the findings of the study, there was a positive and significant relationship between weight efficacy lifestyle and its two subscales of negative emotions and physical discomfort with psychological well-being, and there was a negative and significant relationship between perceived parenting style and all its subscales with psychological well-being. However, $36 \%$ of changes in psychological well-being were predicted by physical discomfort, mother's autonomy support, and mother's warmth.

Conclusion: Overall, the findings of this study support the role of weight efficacy lifestyle and perceived parenting styles variables in student psychological well-being.

\section{"Corresponding Author:}

Seyedeh Arezoo Kazemi, MA.

Address: Department of Psychology, Faculty of Education and Psychology, Azarbaijan Shahid Madani University, Tabriz, Iran.

Phone: +98 (903) 9113468

E-mail: aakazemi21@yahoo.com 


\section{Introduction}

aving a life with appropriate quality has always been a dream for humans and $\mathbf{H}$ finding the concept of a good life and how to achieve it has long been considered [1]. Many psychologists' attention has been focused on the positive aspects of life that have led to the development of a new psychological branch called positive psychology [2]. With the advent of theories, such as Maslow's Theory of Self-Actualization, Rogers' Theory of the Characteristics of a Fully Functioning Person, Allport's Theory of the Mature Human Being, often known as the Theory of Maturity, and the Positive Psychology Movement, that all emphasized the presence of positive characteristics and the development of personal mental health skills, a group of psychologists used the term "Psychological Well-being" instead of "Mental Health" [3] because they believed that this term mostly expresses the positive dimensions of the mind [4].

The Psychological Well-being Model is one of the most important well-being theories suggested by Ryff [5] analyzing the previous literature about well-being and satisfaction. Psychological Well-being is defined as the inner experience of positive emotions, the feeling of exuberance, emotional health, the lack of experiencing frustration, the total satisfaction with life, and also the attempt to satisfy the potential abilities that play a major role in the promotion of general health and the improvement of psycho-social well-being [6]. In other words, psychological well-being is usually conceived as a combination of positive emotional states, such as happiness and functioning in personal and social life with effectuality [7]. Psychological well-being also means the way people are self-evaluated and able to fulfill different aspects of their lives, such as relationships, support, and occupation [8]. This viewpoint is similar to the initial model by Ryff and Keyes [9] who proposed a multi-dimensional perspective of psychological well-being. Psychological well-being's factors include self-acceptance (having a positive attitude towards oneself), positive relations with others (having warm and intimate relationships with others and also having the feeling of empathy and affection towards all of the human beings), autonomy (having self-sufficiency, independence, and self-regulating behaviors), environmental mastery (having the ability to choose or create an appropriate environment with regard to one's psychological situation), purposeful life (having purpose and meaning in life), and personal growth (having the feeling of personal growth and development) [5].
Self-efficacy is one of the most important predictive factors of behavior that has related to psychological wellbeing [10]. The findings of a majority of studies have shown that eating behavior's self-efficacy is the predictive factor of weight loss and during programs designed and executed for weight loss, it prevents renewed weight gain, increases motivation and commitment to change behavior, encourages patients to search for information sources, and facilitates confrontation with dangerous and tempting situations [11].

Additionally, lasting weight loss requires behavioral guidelines for self-care, practical planning, expanding self-efficacy, autonomy, and motivation. Trying to lose weight can cause stress and make motives and emotions face the lack of energy, and environmental signs for overeating as a result of physiological stimulation [12]. Generally, self-efficacy is an important factor that requires to be scrutinized, attended, and considered in educational programs and weight loss interventions. However, regarding health education, it has been shown that information on healthy and hygienic habits is not sufficient. The procedure for weight loss and the modification and improvement of the lifestyle to prevent the return of obesity is a technical issue and must be carried out under the supervision of a group of experts, such as nutritionists, physicians, and psychologists. Psychology, on the other hand, is the most important science in improving the lifestyle because modifying behavior is the main subject of enhancing the lifestyle [11]. There are three main theories about eating styles. The psychosomatic theory is the first theory. Many people can not distinguish real hunger based on this principle and usually eat in response to emotional conditions. Their eating style is called emotional eating. The second theory, called the Externality Theory, claims that obese individuals eat mostly due to outside stimuli and not from real hunger. This style of eating is called external eating. The third hypothesis, which is the Restraint Theory considers the eating habits of obese people to be due to a diet and thus restricted. In other words, these people are in a paradoxical situation. In other words, there is a controversial state, in which these people are more likely to eat because they are prevented from consuming the prohibited foods. This type of eating is called restrained eating [13].

Interestingly, as the components of psychological well-being, the family is one of the variables that can have a significant impact on people's quality of life and satisfaction [14]. People need a supporter called family on the path to a healthy life and adaptation to the surrounding world. Family is known as the most important factor in shaping attitudes and researchs of Cohen 
and et al, Brennan and et al, and Schaefer [16-18] has shown the fundamental effect of the parenting style on psychological well-being. Each family has a specific method for their children's social and personal education. Such approaches, called parenting strategies, are influenced by different factors, such as cultural, social, political, economic, and related factors [19]. Parenting styles are referred to as methods that affect individual growth in a singular or cooperative manner. Parenting styles can be said to be an attempt by parents to socialize their children [20]. Baumrind from 1991 to 2005 studied two factors that determine the type of parent-child interaction and relationship, namely acceptance-responsiveness and demandingness-control. The dimension of acceptance-responsiveness is representative of the degree of parents' warmth and child protection that leads to an increase in the child's ability to self-affirm, self-respect, and self-confidence. Demandingness-control dimension represents two levels of the child's expectation that his/ her behavior will be regulated and the child's activities supervised [21]. Based on the relationship between demandingness and responsiveness, Baumrind defined three forms of parenting styles: authoritative, authoritarian, and permissive. Authoritative parents are high in sensitivity and demandingness. Authoritarian parents are high in demandingness and low in responsiveness. Permissive parents have a high level of sensitivity and a low level of demand [22]. The child's perception of the parenting style of the parents is different from the parent's perceptions of their own parenting style. In this regard, Grolnick et al. [23] found that the perceived parenting style consisted of three dimensions of involvement, autonomy support, and warmth. The involvement dimension means the parents' positive attention to the child and the amount of time spent engaging actively and noticing the daily activities of the child. The autonomy support dimension includes the support of parents for the child's perspective and the use of skills that improve the child's ability to make choices, self-initiate, make decisions, and solve problems. Lastly, warmth means the consistency of parents' responsiveness, sensitivity attention, encouragement stability, and intimacy towards their child. Special attention has been given to the elements and dimensions of these models in the recent theoretical studies on parenting styles. Authoritative parenting style, based on these studies, includes dimensions, such as warmth, protection, self-regulation, and autonomy. Authoritarian parenting style often involves three dimensions of physical force, verbal hostility, and inexplicable punishments. Finally, the permissive parenting style consists of a vague dimension called indifference [24].
Gholamali Lavasani et al. [25] suggested that authoritarian and permissive perceived parenting styles have a meaningful negative correlation with psychological well-being; however, the authoritative parenting style did not predict psychological well-being. Malekzade et al. [10] also found that the mediating effect of selfefficacy and perceived acceptance-rejection significantly predicted psychological well-being and environmental mastery subscales, including personal growth, the purpose of life, and self-acceptance.

With regard to the importance of psychological well-being in identifying the level of personal well-being (most studies have been conducted on mental well-being) and also because the aim of positive psychology framework is the identification of structures that contribute to wellbeing, the need to study and pay more attention to factors that affect the psychological well-being seems necessary. In this regard, it is important to note university students as a significant proportion of the country's active population, as the absence of psychological well-being can have disruptive effects on their educational performance. The present study aimed at assessing how much the predictive variables will determine the variance in the psychological well-being of university students and also measuring the proportion of each predictive variable in psychological well-being. Therefore, the aim of this study was to examine the relationship between weight efficacy lifestyle dimensions and perceived parental styles dimensions with psychological well-being among university students.

\section{Methods}

This research was a correlational study. The statistical population of the study consisted of all male and female undergraduate and master students of Azarbaijan Shahid Madani University in the academic year 2016-2017, of whim 200 students were selected by random cluster sampling method. Accordingly, from 7 faculties of Azarbaijan Shahid Madani University, 4 faculties of Agriculture, Education and Psychology, Basic Sciences, and Technology were selected, and 50 students from each faculty were selected randomly. Finally, because of no complete answers to the questionnaires, 20 questionnaires were eliminated and the final sample size was 180 students. Regarding demographic features, $65.6 \%$ of the subjects were female and $34.4 \%$ were male. In terms of marital status, $83.89 \%$ of female cases were single and $16.10 \%$ were married and $93.54 \%$ of male cases were single and $6.45 \%$ were married. 
The subjects were then examined using the following tools:

Perceptions of Parents Scale (POPS): Grolnick et al. [23] developed this scale with a version designed for students and children. The scale is developed for subjects who are in the final years of adolescence or a litter older and includes 40 items, of which 20 are for mothers and the other 20 are related to fathers (the sentences for fathers and mothers are repeated in two halves). POPS tests six subscales. For each of the patents, the warmth subscale has 6 phrases, the engagement has 5 phrases, and the support in autonomy has 9 . The response to this scale is based on a 7-point Likert scale. In this continuum, the number 1 stands for total disapproval, 7 stands for total approval and 4 is the average score. The minimum and the maximum grade of each individual in this scale are 40 and 280, respectively. This scale incorporates subscales, such as mother's engagement, father's engagement, mother's autonomy support, father's autonomy support, mather's warmth, and father's warmth. In the main source, the reliability of this scale, using Cronbach's alpha, is between 0.79 and 0.86 ; and in the Persian version, the subscales' Cronbach's alpha coefficients are $0.87,0.93,0.82,0.88,0.84,0.93$, respectively, and 0.83 for the whole scale. The findings of the factor analysis with variance rotation showed that only 40 phrases are consistent with the main version and undergo six-factor loading. In addition, Karshki [26] reported the overall reliability of 0.93 for the scale using Cronbach's alpha, and with regard to the subscales, the following findings were obtained: engagement: 0.64, autonomy support: 0.84 , warmth: 0.83 . Additionally, in the present research, the Cronbach's alpha for the whole scale was 0.91 , and $0.59,0.62,0.72,0.65,0.80$, and 0.79 for the subscales, respectively.

Weight Efficacy Lifestyle Questionnaire (WEL): This questionnaire, was initially developed by Clark et al. [27] to measure the self-efficacy of eating control amongst obese people seeking treatment. It is a selfreporting tool with 20 questions that assess the person's confidence in his ability to control and stop eating in different situations. Questions are answered on a 10-point Likert scale ranging from 0 (not sure) to 10 (completely sure), including subscales of negative emotions, availability, social pressure, physical disturbance, and positive activities. The scores for each question are summed up and divided by 20 in order to calculate the total score for this questionnaire. To measure the score of each subscale, the scores of all the sub-scale questions are again summarized and separated by 4 . The score ranges from 10 to 40 for each subscale, with the higher scores indicating lower levels of confidence and assurance. Clark et al. [27] carried out a systematic analysis using this questionnaire. The original version with 40 questions was used for a sample of 162 overweight individuals and five factors were realized representing 5 supposed dimensions of self-efficacy. Based on the results, the shortened version with 20 questions was also developed and used, as a result of which the entire theoretical framework of this questionnaire was re-approved for 220 participants on a weight loss program. The factor load ranged from 0.62 to 0.92 for these 20 statements. Bababei et al. [28 addressed this questionnaire in Iran, where the Cronbach's alpha for the factors ranged from 0.71 to 0.78 . However, in the current research, the Cronbach's alpha of the whole scale was 0.92 , and for the subscales, it was obtained $0.78,0.71,0.77,0.78$, and 0.73 , respectively.

Psychological Well-being Questionnaire: Keyes and Magyar-Moe [29] developed this questionnaire, which included 18 questions. It was also applied and validated by Golestani Bakht [30] on 57 subjects. During this experiment, the correlation coefficient of the scale was reported to be 0.64 . In addition, the internal consistency coefficient was estimated at 0.80 based on Cronbach's alpha. Tamanayifar and Motaghedifard [31] estimated the internal consistency coefficient of 0.70 based on Cronbach's alpha for this scale. Questions 1, 2, 3, 8, 9, $11,12,13,17$, and 18 are rated conversely in the Questionnaire, and the overall score of all questions will be the psychological well-being score. Cronbach's alpha of the scale in this study was 0.72 .

We obtained the informed permission and consent of the participants and made them informed about being free to leave the study.

Data were also analyzed using SPSS V. 24 software. The Kolmogorov-Smirnov test was also used to measure the normal distribution of data frequency. The inferential statistics, such as frequency, percentage, mean, and standard deviation, and also descriptive statistics, such as Pearson correlation coefficient and simultaneous multiple regression analysis were used.

\section{Results}

The subjects of this study were 180 Azarbaijan Shahid Madani University students, $65.6 \%$ of whom were female and $34.4 \%$ were male. With respect to their academic level, 75.5\% were students who had a bachelor's degree, $17.7 \%$ were students with a Master's degree, and 6.6\% did not mention their academic level. In terms of marital status, $87.2 \%$ were single and $12.8 \%$ were married. 
Table 1. Correlation matrix and central indices and dispersion of variables

\begin{tabular}{|c|c|c|c|c|c|c|c|c|c|c|c|c|c|c|}
\hline Variables & Mean $\pm S D$ & 1 & 2 & 3 & 4 & 5 & 6 & 7 & 8 & 9 & 10 & 11 & 12 & 13 \\
\hline $\begin{array}{l}\text { 1. Negative } \\
\text { emotions }\end{array}$ & $3.77 \pm 2.35$ & 1 & & & & & & & & & & & & \\
\hline 2. Availability & $4.17 \pm 2.17$ & $0.56^{* *}$ & 1 & & & & & & & & & & & \\
\hline 3. Social pressure & $3.81 \pm 2.18$ & $0.56^{* *}$ & $0.71^{* *}$ & 1 & & & & & & & & & & \\
\hline $\begin{array}{l}\text { 4. Physical distur- } \\
\text { bance }\end{array}$ & $3.75 \pm 2.30$ & $0.75^{* *}$ & $0.66^{* *}$ & $0.76^{* *}$ & 1 & & & & & & & & & \\
\hline $\begin{array}{l}\text { 5. Positive } \\
\text { activities }\end{array}$ & $4.04 \pm 2.18$ & $0.53^{* *}$ & $0.74^{* *}$ & $0.66^{* *}$ & $0.65^{* *}$ & 1 & & & & & & & & \\
\hline $\begin{array}{l}\text { 6. Weight efficacy } \\
\text { lifestyle }\end{array}$ & $3.83 \pm 1.81$ & $0.77^{* *}$ & $0.81^{* *}$ & $0.81^{* *}$ & $0.86^{* *}$ & $0.79^{* *}$ & 1 & & & & & & & \\
\hline $\begin{array}{l}\text { 7. Mother's } \\
\text { warmth }\end{array}$ & $32.36 \pm 6.71$ & -0.001 & -0.001 & 0.01 & -0.02 & 0.05 & -0.03 & 1 & & & & & & \\
\hline 8. Father's warmth & $30.87 \pm 6.91$ & 0.00 & 0.05 & 0.02 & -0.04 & 0.05 & -0.02 & $0.57^{* *}$ & 1 & & & & & \\
\hline $\begin{array}{l}\text { 9. Mother's } \\
\text { autonomy Support }\end{array}$ & $42.62 \pm 8.15$ & -0.04 & -0.10 & -0.06 & -0.09 & -0.07 & $-0.11^{*}$ & $0.75^{* *}$ & $0.54^{* *}$ & 1 & & & & \\
\hline $\begin{array}{l}\text { 10. Father's } \\
\text { autonomy Support }\end{array}$ & $41.37 \pm 7.37$ & -0.10 & -0.02 & -0.06 & $-0.12^{*}$ & -0.03 & $-0.12^{*}$ & $0.50^{* *}$ & $0.72^{* *}$ & $0.53^{* *}$ & 1 & & & \\
\hline $\begin{array}{l}\text { 11. Mother's } \\
\text { engagement }\end{array}$ & $24.12 \pm 5.09$ & -0.03 & -0.09 & -0.05 & -0.05 & -0.00 & -0.09 & $0.64^{* *}$ & $0.41^{* *}$ & $0.66^{* *}$ & $0.44^{* *}$ & 1 & & \\
\hline $\begin{array}{l}\text { 12. Father's } \\
\text { engagement }\end{array}$ & $22.18 \pm 5.51$ & -0.01 & -0.06 & -0.06 & -0.05 & -0.02 & $-0.10^{*}$ & $0.44^{* *}$ & $0.63^{* *}$ & $0.47^{* *}$ & $0.61^{* *}$ & $0.57^{* *}$ & 1 & \\
\hline $\begin{array}{l}\text { 13. Perceived } \\
\text { parenting Style }\end{array}$ & $193.0 \pm 32.67$ & -0.04 & -0.04 & -0.02 & -0.07 & -0.00 & -0.10 & $0.83^{* *}$ & $0.80^{* *}$ & $0.84^{* *}$ & $0.80^{* *}$ & $0.73^{* *}$ & $0.75^{* *}$ & 1 \\
\hline $\begin{array}{l}\text { 14. Psychological } \\
\text { well-being }\end{array}$ & $58.69 \pm 12.29$ & $0.13^{*}$ & 0.07 & 0.09 & $0.17^{* *}$ & 0.03 & $0.13^{* *}$ & $-0.35^{* *}$ & $-0.42^{* *}$ & $-0.49^{* *}$ & $-0.46^{* *}$ & $-0.42^{* *}$ & $-0.45^{* *}$ & $-0.54^{* *}$ \\
\hline
\end{tabular}

To explore and describe the resulting psychological well-being data from the sample, weight efficacy lifestyle and its dimensions, and perceived parenting style and its dimensions, central tendency measure and dispersion index were used. Table 1 presents the measures of the central tendency dispersion index and correlation matrix of the variables.

There was a positive and significant relationship between weight efficacy lifestyle and its two subscales of negative emotions and physical disturbance, (Table 1). There was also a negative and significant relationship between perceived parenting style and its all subscales and psychological well-being.

Then, after ensuring the presumptions of the regression (normalization, investigation of outliers, the linearity of the relationship, independence of errors, and the sufficient number of samples), in order to specify the impact of each aspect of lifestyle, including negative emotions, availability, social pressure, physical disturbance, and positive activities, on weight, and also to specify the impact of various aspects of perceived parenting, such as mother's warmth, mother's autonomy support, mother's engagement, father's warmth, father's autonomy sup- port, and father's engagement, on predicting the psychological well-being, the simultaneous multiple regression analysis was utilized the results are included in Table 2.

Based on the results of Table 2, the correlation coefficient $(\mathrm{R}=0.60)$ between predictive and psychological well-being variables and as a result of which, $\mathrm{R}^{2}$ of 0.36 , indicated that $36 \%$ of psychological well-being is based on the weight efficacy lifestyle and perceived parenting style and its subscales. The results of variance analysis showed that $\mathrm{F}$ had a meaningful value $(\mathrm{P}<0.0001$; $\mathrm{F}=14.98$ ). Thus, the predictive variables could fully predict psychological well-being. In addition, the regression coefficient significance test indicated that these variables will determine the variance of psychological well-being with the negative sign representing the orientation of the relationship: mother's autonomy support $(\mathrm{P}<0.05 ; \beta=$ -0.28), mother's warmth $(\mathrm{P}<0.05 ; \beta=0.24)$, and physical disturbance $(\mathrm{P}<0.05 ; \beta=0.20)$.

\section{Discussion}

The results of this study showed that there was a significant and positive correlation between weight efficacy lifestyle and its two subscales, namely negative emo- 
Table 2. Summary of the simultaneous regression analysis model of studied variables affecting the psychological well-being

\begin{tabular}{|c|c|c|c|c|c|c|c|c|}
\hline Variables & $\beta$ & $\mathbf{t}$ & Sig. & $\mathbf{R}$ & $\mathbf{R}^{2}$ & SE & $\mathbf{F}$ & Sig. \\
\hline Constant & - & 25.74 & 0.001 & 0.60 & 0.36 & 10.01 & 14.98 & 0.001 \\
\hline Negative emotions & 0.05 & 0.79 & NS & & & & & \\
\hline Availability & -0.03 & -0.46 & NS & & & & & \\
\hline Social pressure & 0.01 & 0.15 & NS & & & & & \\
\hline Physical disturbance & 0.20 & 2.18 & 0.05 & & & & & \\
\hline Positive activities & -0.10 & -1.31 & NS & & & & & \\
\hline Weight efficacy lifestyle & -0.06 & -0.46 & NS & & & & & \\
\hline Mother's warmth & 0.24 & 2.14 & 0.05 & & & & & \\
\hline Father's warmth & -0.01 & -0.13 & NS & & & & & \\
\hline Mother's autonomy support & -0.28 & -2.14 & 0.05 & & & & & \\
\hline Father's autonomy support & -0.06 & -0.60 & NS & & & & & \\
\hline Mother's engagement & -0.08 & -0.97 & NS & & & & & \\
\hline Father's engagement & -0.12 & -1.22 & NS & & & & & \\
\hline Perceived parenting style & -0.27 & -0.68 & NS & & & & & \\
\hline
\end{tabular}

tions and physical disturbance with the psychological well-being and also, there was a negative and meaningful correlation between perceived parenting style and its all subscales with the psychological well-being. This is in accordance with the results of Cohen et al. [16] and cannot be justified with those of Malekzadeh et al. [10]. It seems that this disagreement is due to the age group difference between the subjects of the two studies.

We found that a mother's autonomy support negatively predicted psychological well-being, which is not in line with the results of Malekzadeh et al. [10]. Autonomy support results in parent validation of their child's perspectives and can lead to the use of approaches that enable the collection, self-initiation, choice, and problem-solving abilities. Our observation seems to be due to the full support of the mother and the non-existence of father support. In other words, if autonomy support comes from both father and mother, it can lead to environmental superiority, which is one of the components of psychological wellbeing. It is important to note that this research is among the first to use the POPS to determine psychological wellbeing. Thus, expanding the results demand more research.

Another result was that the mother's warmth was significantly predictive of psychological well-being, which is consistent with the results of Malekzadeh et al. [10] and Cohen et al. [16]. Mother's warmth includes factors, such as responsibility, attentiveness, encouragement, constancy, and mother's intimacy with the child [23]. It seems that a high score in this aspect can lead to an increase in self-acceptance, interpersonal relationships, and personal growth that are some of the psychological well-being characteristics. Thus, it seems that a mother's warmth can lead to an increase in psychological well-being.

Our final finding was that physical disturbance predicts psychological well-being positively. This can be explained by incorporating factors, such as physical exhaustion, headache, and unpleasant feelings that contribute to resistance against eating food. Therefore, it seems that a weight efficacy lifestyle can effectively stop emotional eating and consequently, weight gain by increasing eating self-efficacy; this is supported by the findings of Swencionis et al. [32], who indicated that weight loss can lead to an increase in psychological well-being. In other words, this finding is in full accordance with the theory of eating psychosomatically. Many people cannot detect real hunger on the basis of this theory and usually eat as a reaction to emotional states, which is called emotional eating. Therefore, higher scores in physical disturbance or the ability of the person to stop eating in stressful situ- 
ations will minimize emotional eating and improve psychological well-being by changing the weight.

\section{Conclusion}

According to the results of the simultaneous regression analysis to predict psychological well-being on the students based on weight efficacy lifestyle and its scales and perceived parenting and its scales, the physical disturbance (from the WEL), and the mother's warmth and autonomy support (from the POPS) could meaningfully determine the $36 \%$ of the variance of psychological well-being in the students. The findings of this study support the effect of weight efficacy lifestyle and perceived parenting styles on the psychological well-being of the students.

The results of this study are significant because psychological well-being is an important factor in the students' satisfaction with life and acceptable educational performance. In addition, psychological well-being is considered to be a remarkably effective factor in terms of hygiene, treatment, prevention, reduction of the prevalence of diseases, and stopping the side effects of psychological diseases and disorientation, especially among students. Thus, it is proposed that the psychological well-being of the students can be increased using personal and group training for weight efficacy lifestyle in universities and also by holding classes and offering packages to guide the parents about the nature and types of connection with the children.

\section{Ethical Considerations}

\section{Compliance with ethical guidelines}

All ethical principles are considered in this article.

\section{Funding}

This research did not receive any grant from funding agencies in the public, commercial, or non-profit sectors.

\section{Authors' contributions}

Data collection and analysis: Seyedeh Arezoo Kazemi; Manuscript preparation: Both authors.

\section{Conflict of interest}

The authors declared no conflict of interest.

\section{References}

[1] Golshan M, Baradaran M. [Relationship between temperament and character, sence of coherence and psychological well-being of students (Persian)]. Contemp Psychol. 2017; 12(Special Issue):1465-8.

[2] Mahjobnavaz F, Anbardabaghian S, Hashemi T, Mashinchi Abbasi N. [Emotional intelligence and psychological well-being in students (Persian)]. Contemp Psychol. 2017; 12(Special Issue):1509-13.

[3] Rezaian M, Ghadiri Foroushani S. [The Effects of Positive Psychotherapy on the Psychological well-being of Married Female Students (Persian)]. Contemp Psychol. 2017; 12(Special Issue):798-801.

[4] Kamran Pourjahromi F, Rahimi Ch, Chitsazi M. [Psychological Hardiness, Self-efficacy and Psychological well-being in students (Persian)]. Contemp Psychol. 2017; 12(Special Issue):1395-9.

[5] Ryff CD. Happiness is everything, or is it? Explorations on the meaning of psychological well-being. Personal Soc Psychol. 1989; 57(6):1069-81. [DOI:10.1037/0022-3514.57.6.1069]

[6] Raigani FS, Telkabadi Arani Z, Davari Z, Shakeri S, Motamedi Fard M, Goli ZS. [Parent's Psychological and Social Well-being Predict Children's Separation Anxiety (Persian)]. Contemp Psychol. 2017; 12(Special Issue):747-50.

[7] Winefield HR, Gill TK, Taylor AW, Pilkington RM. Psychological well-being and psychological distress: Is it necessary to measure both? Psych Well-Being 2012; 2(3):1-14. [DOI:10.1186/2211-1522-2-3]

[8] Cripps K, Zyromski B. Adolesxents psychological well-being and perceived parental involvement: Implications for parental involvement in middle schools. RMLE. 2009; 33(4):1-13. [DOI:10.1080/19404476.2009.11462067]

[9] Ryff CD, Keyes CL. The structure of psychological wellbeing revisited. J Pers Soc Psychol. 1995; 69(4):719-27. [DOI:10.1037/0022-3514.69.4.719] [PMID]

[10] Malekzade L, Heidari M, Pakdaman Sh, Tahmassian K The mediator relationship/effect of subsets of applied parenting styles and self-efficacy on psychological well-being in adolescents. J Family Res. 2014; 10(1):113-26. https://jfr.sbu. ac.ir/article_96657.html

[11] Navidian A, Abedi M, Baghban I, Fatehizadeh M, Poursharifi H. [Reliability and Validity of the weight efficacy lifestyle questionnaire in overweight and obese individuals (Persian)]. J Behav Sci. 2009; 3(3):217-22. https://iranjournals.nlai.ir/bitstream/handle/123456789/218433/F7A05C26220036A5B51FC2343EAEB14C.pdf?sequence=-1

[12] Duarte C, Stubbs J, Pinto-Gouveia J, Matos M, Gale C, Morris $\mathrm{L}$, et al. The impact of self-criticism and self-reassurance on weight-related affect and well-being in participants of a commerical weight management programme. Obes Facts. 2017; 10(2):65-75. [DOI:10.1159/000454834] [PMID] [PMCID]

[13] Salehi Fadardi J, Maddan Shoorcheh R, Nemati M. A comparison of motivational structure and eating bahaviors between overweight and obese and normal weight women. J Fundament Mental Health. 2011; 13(2):170-81. https:/ / www. sid.ir/FA/JOURNAL/ViewPaper.aspx?ID=146497 
[14] Gomez V, Kings F, Bangereter A, Grob A. The influence of personality and life events on subjective well-being from a life span persoective. J Res Personal. 2009; 43(3):345-54 [DOI:10.1016/j.jpr.2008.12.014]

[15] Asghari F, Tarverdizadeh Sh, Saadat S. Relationship between parenting and attachment styles with psychological wll-being among female students of Payam Nor University of Talesh. Beyhagh. 2014; 19(3):57-67. http:// beyhagh.medsab. ac.ir/article_698.html

[16] Cohen M, Mansoor D, Gagin R, Lorber A. Perceived parenting style, self-esteem and psychological distress in adolescents with heart disease. Psychol Health Med. 2008; 13(4):381-8. [DOI:10.1080/13548500701842925] [PMID]

[17] Brennan PA, Le Brocque R, Hammen C. Maternal depression, parent-child relationships, and resilient outcoms in adolescence. J Am Acad child Adolesc Psychiatry. 2003; 42(12):1469-77. [DOI:10.1097/00004583-200312000-00014] [PMID]

[18] Schaefer ES. Children's reports of Parental behavior: An inventory. Child Dev. 1965; 36(2):413-24. [DOI:10.2307/1126465] [PMID]

[19] Veis Karami H, Sabzian S, Pirjavid F, Garavand H. [Study the relationship between perceived parenting styles with selfregulatory learning strategies students of Ferdowsi University of Mashhad (Persian)]. Res School Virtual Learning. 2014; 2(5):81-94. http://etl.journals.pnu.ac.ir/article_1376.html

[20] Ahmedbookani S, Khodabakhsh MR, Etemadi A, Kiani F. The effects of Religions orientation and Parenting Styles on students Mental Health. J Commun Health. 2013; 7(2):20-9. http://chj.rums.ac.ir/article_45694_en.html

[21] Pakdaman Sh, Khanjani M. The role of perceived parenting in the relationship between attachment and collectivism styles among university students. Soc Psychol Res. 2011; 1(4):81-102. https://www.sid.ir/Fa/Journal/ViewPaper. aspx?ID=163702

[22] Soltannezhad S, Sa'dipour S, Asadzadeh H. Relationship among perceived parenting styles, procrastination and selfhandicapping. Educ Psychol. 2015; 11(38):1-22. http://jep. atu.ac.ir/article_3927.html

[23] Grolnick WS, Deci EL, Ryan RM. Internalization within the family: The self-determination theory perspective. In Gruses IE, Kuczynski L, editors. Parenting and Childrens Internalization of Values: A Handbook of Contemporary Theory. New York: Wiley; 1997. https://www.researchgate.net/publication/301325937_Internalization_within_the_family_The self-determination_theory_perspective

[24] Laali-Faz A, Askari AA. [The power of predicting percieved parenting styles and demographic variables on girl student's loneliness feeling (Persian)]. J Fundament Mental Health. 2008; 10(37):71-8. https://www.sid.ir/fa/journal/ ViewPaper.aspx?id=73303

[25] Gholamali Lavasani M, Borhanzadeh Sh, Afzali L, Hejazi E. The relationship between perceived parenting style, social support with psychological well-being. Procedia Soc Behav Sci. 2011; 15:1852-6. [DOI:10.1016/j.sbspro.2011.04.014]

[26] Karshki H. The role of motivational patterns and environmental perceptions in self-regulatory learning of secondary school students in Tehran [PhD. dissertation]. Tehran: University of Tehran; 2008.
[27] Clark MM, Abrams DB, Niaura RS, Eaton CA, Rossi JS Self-efficacy in weight management. J Consult Clin Psychol. 1991; 59(5):739-44. https://www.ncbi.nlm.nih.gov/pubmed/1955608

[28] Babai S, Khodapanahi MK, Sadeghpoor BS. [Validating and investigating reliability of the weight efficacy life style questionnaire (Persian)]. J Behav Sci. 2008; 2(1):75-81. https:/ / www.sid.ir/Fa/Journal/ViewPaper.aspx?id=83052

[29] Keyes CLM, Magyar-Moe JL. The measurement and utility of adult subjective well-being. In: Lopez SJ, Snyder R, editors, Positive Psychological Assessment: Handbook of Models and Measures. Washington, D.C.: American Psychological Association; 2003. [DOI:10.1037/10612-026]

[30] Golestanibakht T. Model of subjective well and joy in the population of Tehran [PhD. dissertation]. Tehran: Alzahra University; 2007.

[31] Tamannaeifar MR, Motaghedifard M. Subjective well-being and its sub-scales among students: The study of role of creativity and self-efficacy. Think Skills Creativ. 2014; 12:37-42. [DOI:10.1016/j.tsc.2013.12.003]

[32] Swencionis C, Wylie-Rosett J, Lent MR, Ginsberg M, Cimino C, Wassertheil-Smoller S, et al. Weight change, psychological well-being, and vitality in adults participating in a cognitive-behavioral weight loss program. Health Psychol 2013; 32(4):439-46. [DOI:10.1037/a0029186] [PMID] [PMCID] 